\title{
Climate Characteristics over Southern Highlands Tanzania
}

\author{
Yassin Mbululo $^{1,2}$, Fatuma Nyihirani ${ }^{3}$ \\ ${ }^{1}$ School of Environmental Studies, China University of Geosciences, Wuhan, China \\ ${ }^{2}$ Sokoine University of Agriculture, Morogoro, Tanzania \\ ${ }^{3}$ Mzumbe University, Morogoro, Tanzania \\ Email: ymbululo@yahoo.com
}

Received June 24, 2012; revised July 28, 2012; accepted August 9, 2012

\begin{abstract}
This study was conducted to examine the climate characteristic of southern highland Tanzania (Latitude $6^{\circ} \mathrm{S}-12^{\circ} \mathrm{S}$ and Longitude $29^{\circ} \mathrm{E}-38^{\circ} \mathrm{E}$ ). The study findings reveal that rainfall over the region is linked with SST over the Indian Ocean, where warmer (cooler) western Indian Ocean is accompanied by high (low) amount of rainfall over Tanzania. During wet (dry) years, weaker (stronger) equatorial westerlies and anticyclone (cyclonic) anomaly over the southern tropics act to reduce (enhance) the export of equatorial moisture away from East Africa. The wettest (driest) season was found to be 1978/79 (1999/00) which can be classified as the severely wet (moderate drought). Two different modes of rainfall have been identified at time scale of 1.5 and 6 years which have been associated with the quasi biennial oscillation (QBO) and El Nino Southern Oscillation (ENSO), respectively.
\end{abstract}

Keywords: Tanzania; Climate Characteristics; Dominant Periodicity Mode

\section{Introduction}

Tanzania has been experiencing unreliable and unpredictable rainfall patterns for the past few decades. This trend is an alarming problem to agricultural productivity and wellbeing of the country since the sector is the backbone of the country economy. The north and northern coast of the country tend to exhibit bimodal rainfall pattern from March to May and October to November. These patterns are locally known as the "long" or "Masika" and "short" or "Vuli" rainfall seasons associated with the northward and southward movement of the ITCZ, respectively [1-3]. The southern, central and western parts of the country exhibit unimodal rainfall pattern from November to April, the period which coincides with southern hemisphere summer. Southern highland Tanzania (latitude $6^{\circ} \mathrm{S}-12^{\circ} \mathrm{S}$ and longitude $29^{\circ} \mathrm{E}-38^{\circ} \mathrm{E}$ ) which is studied here is the major cereal producing region. Since the economy of the country depends mostly on rain fed agriculture, therefore the country is vulnerable to the impacts of the rainfall variability.

Over Tanzania, few studies on rainfall variability have been done, mainly are focusing on the bimodal rainfall areas (e.g. $[1,4,5])$ and ignoring the unimodal rainfall areas. The importance of these unimodal rainfall areas lies on the fact that, they are the major cereal producing areas and catchment areas for the rivers which have been tapped for hydroelectricity power generation [2]. Nevertheless, rainfall variability over the East Africa with rela- tion to regional and remote atmospheric and oceanographic parameters has been studied by many researchers (e.g. [3-11]).

Goddard and Graham [6] experiment on Atmospheric General Circulation Model (AGCM) suggests the Indian Ocean sea surface temperature (SST) to be exerting a greater influence over the East and Central Africa rainfall than the Pacific ocean. They also found a considerable modification of convective activities over equatorial Africa and the tropical Indian Ocean to be directly linked by the Pacific Ocean. Saji et al. [12] showed an EastWest dipole mode in the Indian Ocean SST anomalies that is coupled to the atmospheric zonal circulation. They also found Indian Ocean Dipole (IOD) to have significant correlation with East African rains where the rainfall is increased during a positive event and decreased during a negative event. Study by Clark et al. [13] demonstrated the strong correlation which exists between Indian Ocean SST and East African short rains. The authors ascribe the pattern to reoccurring coupled ocean atmosphere phenomena (IOD).

Several other studies (e.g. [7,14]) have tried to delineate homogeneous rainfall region over East Africa and Tanzania in particular. Basalirwa et al. [14] performed principal component analysis and delineate Tanzania into 15 homogeneous rainfall regions based on the network of 150 widely distributed rainfall stations. Indeje et al. [7] performed another principle component analysis and simple correlation analyses using a network of 136 rain- 
fall stations over East Africa. Their analyses yielded 8 homogeneous rainfall regions over East Africa, among them, 5 were found in Tanzania.

Nicholson and Entekhabi [15] have demonstrated the interannual variability of rainfall in much of Africa to be characterized by strong quasi periodic fluctuations in 2.2 $2.4,2.6-2.8,3.3-3.8$ and $6.0-6.3$ years spectral bands. The author acknowledges the presence of other distinct quasi periodicities which are evident throughout equatorial and southern Africa. Study by Indeje and Semazzi [16] found rainfall oscillates in East Africa to have dominant periodicity of between $1.7-2.5$ and 4 - 5 years, which appear to be related to quasi biennial oscillations (QBO) and ENSO events respectively. Therefore, it is the interest of this paper to find out the characteristics of the rainfall over southern highlands Tanzania and the reasons for the observed characteristics since the study area is of significance importance to the economy of the country.

\section{Data and Methodology}

\subsection{Data}

The data used in this study comprises monthly mean rainfall data from 16 meteorological stations found in southern highlands Tanzania for the duration of 41 years from 1970 to 2010. These data were obtained from the Tanzania Meteorological Agency (TMA) where the name and geographical positions of these stations have been presented in Table 1. As the source of the climate rich data sources, monthly mean zonal and meridional winds data set stored at $2.5^{\circ} \times 2.5^{\circ}$ grid boxes, from National Centre for Environmental Prediction (NCEP)/National Center for Atmospheric Research (NCAR) reanalysis [17], Kaplan SST anomaly data stored at $5^{\circ} \times 5^{\circ}$ grid boxes, Global Ocean Surface Temperature Atlas (GOSTA) data set [18] were used. NCEP/ NCAR data has been used in numerous climatological studies in Tanzania, such as those of Mpeta [2]; Mapande and Reason [8,19] among others and yielded promising results.

Southern highland Tanzania (latitude $6^{\circ} \mathrm{S}-12^{\circ} \mathrm{S}$ and longitude $29^{\circ} \mathrm{E}-38^{\circ} \mathrm{E}$ ) which is studied here exhibits unimodal rainfall pattern and the rainfall tends to start in November to April. Four regions (Iringa, Mbeya, Rukwa and Ruvuma) shown in Figure 1 were used to study the climate characteristics of the region.

\subsection{Methodology}

In order to study rainfall characteristics over an area and at the same time to capture mechanisms which cause that characteristic, the Standardized Precipitation Index (SPI) method was used. The SPI is the probability index which was developed by McKee et al. [20] to give better rep-

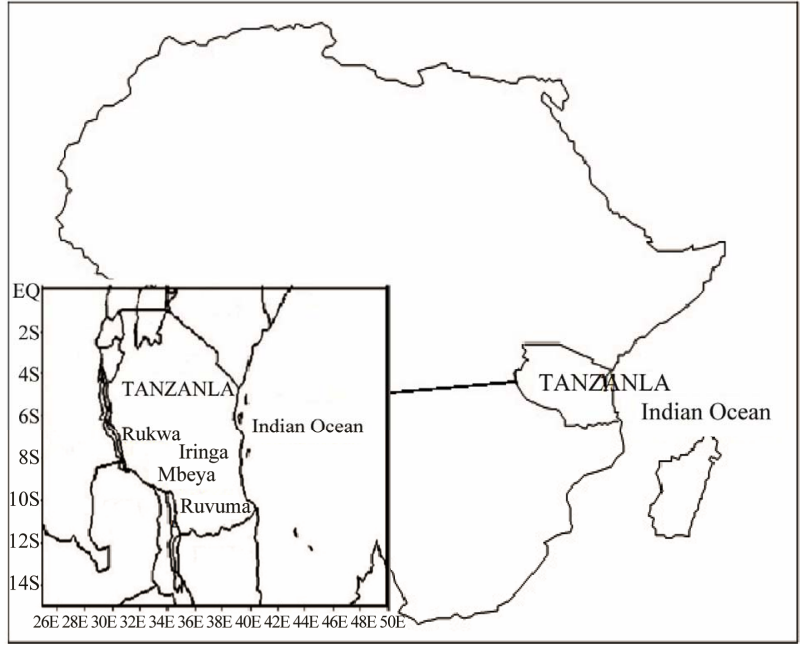

Figure 1. Map of Tanzania showing the study area, Iringa, Mbeya, Rukwa and Ruvuma region.

Table 1. Name and geographical positions of meteorological stations over southern highlands Tanzania

\begin{tabular}{ccc}
\hline Station Name & Latitude (S) & Longitude (E) \\
\hline Iringa Met Stn (Nduli) & $7.60^{\circ}$ & $35.80^{\circ}$ \\
Ludewa bomani & $10.00^{\circ}$ & $30.40^{\circ}$ \\
Njombe bomani & $9.30^{\circ}$ & $34.80^{\circ}$ \\
Iringa Experimental Stn & $7.46^{\circ}$ & $35.41^{\circ}$ \\
Kyela boma & $9.35^{\circ}$ & $33.51^{\circ}$ \\
Tukuyu Agric & $9.10^{\circ}$ & $33.35^{\circ}$ \\
Mitalula & $9.23^{\circ}$ & $33.37^{\circ}$ \\
Mbimba Coffee Research & $9.40^{\circ}$ & $32.58^{\circ}$ \\
Mbarali Irr. Scheme & $8.40^{\circ}$ & $34.15^{\circ}$ \\
Mbeya Met & $8.56^{\circ}$ & $33.28^{\circ}$ \\
Mpanda Boma & $6.20^{\circ}$ & $31.50^{\circ}$ \\
Kisanga hydromet & $7.18^{\circ}$ & $36.47^{\circ}$ \\
Namanyere-Nkansi & $7.31^{\circ}$ & $31.30^{\circ}$ \\
Sumbawanga Agric Stn & $7.57^{\circ}$ & $31.36^{\circ}$ \\
Tunduru Agriculture & $11.60^{\circ}$ & $37.22^{\circ}$ \\
Songea Airfield & $10.40^{\circ}$ & $35.35^{\circ}$ \\
\hline
\end{tabular}

resentation of abnormal wetness and dryness [21]. Since its development, the index has gained increasing acceptance in the United States and other parts of the world as a valuable tool for monitoring drought. It is currently being used by the U.S National Drought Mitigation Center, the Western Regional Climate Center, as well as the Colorado Climate Center [22,23]. The index uses only precipitation data thus making the analysis possible even 
in the absence of other parameters.

The SPI is essentially a standardizing transform of the probability of the observed precipitation. It can be computed for a precipitation total observed over any duration desired by a user (e.g. 1 month SPI, 3 month SPI, 6 month SPI, 12 month SPI, 24 month SPI etc.); short term durations of the order of months may be important to agricultural interests while long term durations spanning years may be important to water resources management purpose because of the slow inherent responses in water bodies to rainfall changes [22-24]. The method is capable of returning essential parameters after the analysis such as severity, magnitude, and frequency of the drought. Heim [24] reveals that, even though index was developed purposely for use in Colorado, it can be applied universally to any location. Furthermore, Manatsa et al. [23] found the index to be temporarily and spatially comparable, independent of geographical and topographical differences, and even relevant in regions with diverse rainfall patterns.

For the purpose of brevity of this study, a "black box" software package was downloaded

(http://www.drought.unl.edu/MonitoringTools/Download ableSPIProgram.aspx) and used for computation for which the input is a rainfall data time series and the output is the SPI. Details on the mathematical computation of SPI may be found in Guttman [21]; Bordi et al. [22] and Lloyd-Hughes and Saunders [25] among others.

\subsection{Regional SPI}

To calculate the Regional SPI, aerial average stations 6-month scale SPI values for the month of April was taken. This 6 month scale counts from November of the previous year to April of the current year. Specifically, Regional SPI is defined by

$$
\text { Regional } \mathrm{SPI}_{y}=\left(\frac{1}{N}\right) \sum_{i=1}^{N} \mathrm{SPI}_{y}
$$

where $N$ is the number of the regional stations operating in the year $y$ (in this case $N=16$ and $y=1971,1972 \ldots$ 2010). SPI values, Percentage of occurrence and nominal class descriptions have been presented in Table 2 .

\section{Results and Discussion}

\subsection{Region Standardized Precipitation Index}

Figures 2(a)-(d) show the Standardized Precipitation Index (SPI) for one month for Iringa, Mbeya, Rukwa and Ruvuma region respectively. Observational study on these SPI figures shows substantial interannual variability of rainfall for each station. Moreover, some degree of persistence in rainfall anomalies can be seen from each station. The positive (negative) SPI value shows the rainfall of above (below) normal and the number is the magnitude of the departure from normal.

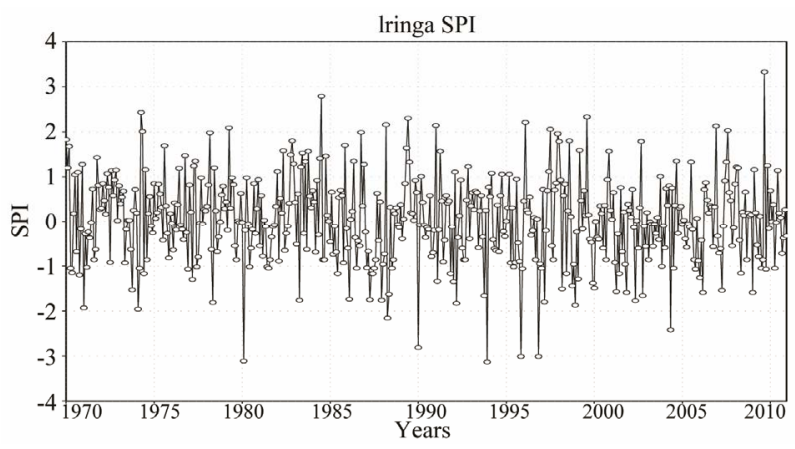

(a)

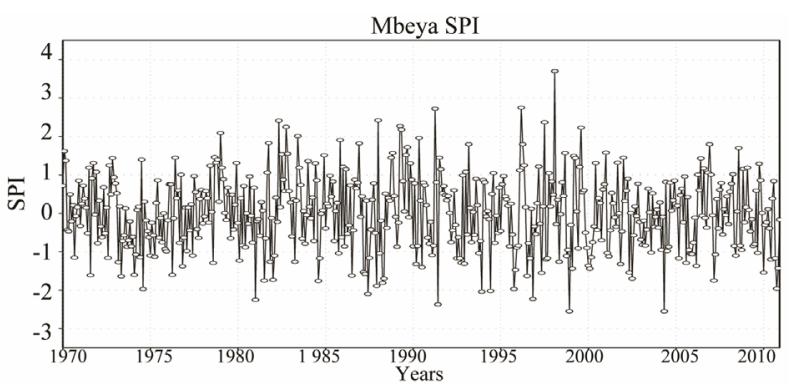

(b)

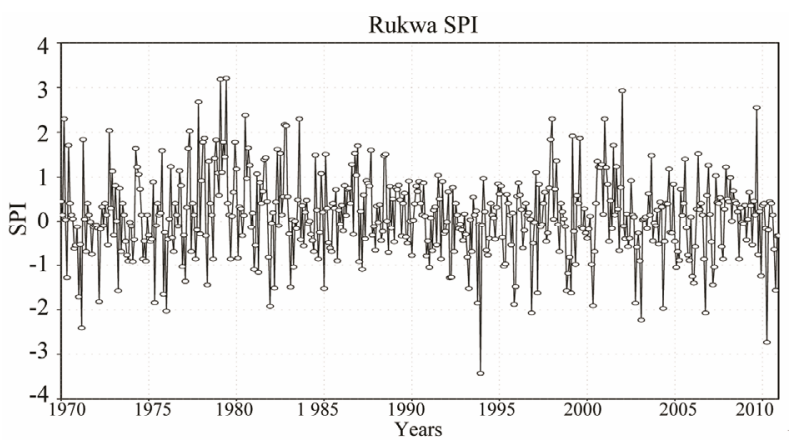

(c)

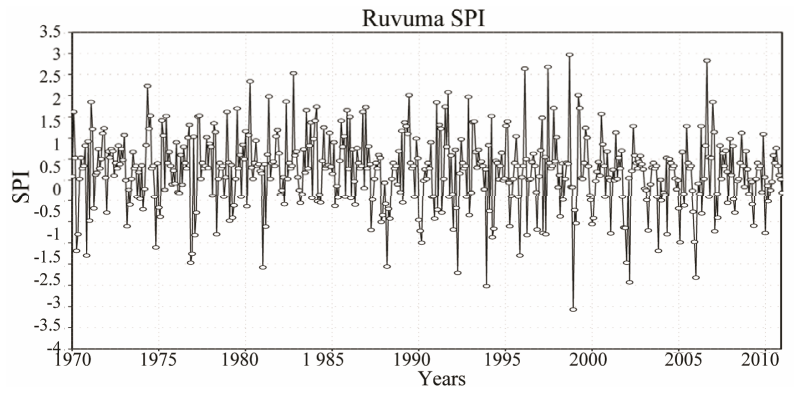

(d)

Figure 2. Schematic representation of Standardized Precipitation Index (SPI) for one month period from January 1970 to December 2010. The $x$-axis represents Years and y-axis represents Amplitude of SPI value. (a) Iringa (b) Mbeya (c) Rukwa (d) Ruvuma region.

\subsection{Regional Standardized Precipitation Index}

In order to relate rainfall demand with practical applications, 6-month time steps of SPI for the November to 
April rain season have been applied in this study. During these months is when the agricultural activities are taking place such as plowing and seed planting so the soil moisture demand is at maximum level, therefore relation of this period is done to mean rainfall amount. Most of the annual rainfall experienced in southern highland Tanzania occurs during this period, and as such, water availability for vegetation is determined primarily by the amount of seasonal rainfall alone. So this seasonal rainfall is the most important single factor for water availability in agricultural activities. The 6-month scale is not only suitable in this research work, but it is also the most common used time scale for regional agricultural drought. Other research works which used this time scale are like those of Manatsa et al. [18]; Ntale and Gan [25] among others.

Moreover, other months which fall outside the growing period (May to October) will not be analyzed because the region during this period is normally virtual dry. In any case, the rainfall that falls within this period mostly goes to waste since crop growing is not undertaken during this period. Thus, 6-month SPI analyzed during this dry period may be misleading in the sense that large negative or positive SPI values may be associated with rainfall not very different from the mean. This is because during the dry periods, the mean total will be small, and hence, relatively small deviations on either side of the mean could have large negative or positive SPI values.

Figure 3 represents the regional SPI (Iringa, Mbeya, Rukwa and Ruvuma) for the duration of 6-month. The plot shows the departures in November to April from $1970 / 71$ to $2009 / 10$ seasons for the region where the year axis refers to the April month (i.e. For 1970/71 season, it represent November of 1970 to April of 1971) of a given season. Although there are some variations in magnitude of the anomalies for each year, the region is experiencing the normal rainfall as the SPI values are at the range of -0.523 to 0.523 values as indicated in Table 2 .

In order to shed more light on the regional SPI, the Mexican hat wavelet method was used to reveal the rainfall characteristics of the region. Wavelet representation for the regional SPI presented in Figure $\mathbf{4}$ as contour maps shows the largest power at the time scale of 4 to 8 years particularly in the 1970 s to 1990 s, and time scale of 2 to 4 years in the 1990s to 2005s. Figure 5 shows the series of purple (shaded) and white (unshaded) bands with numbers representing powers. The purple band represents rainfall of above normal while the white band represents rainfall of below normal. The dominant periodicity mode is seen at the time scale of 1.5 and 6 years which may be associated with the quasi biennial oscillation (QBO) and El Nino Southern Oscillation (ENSO). Similar results to this quasi periodic oscillation over the region have been presented by Mpeta [2]; Nicholson and

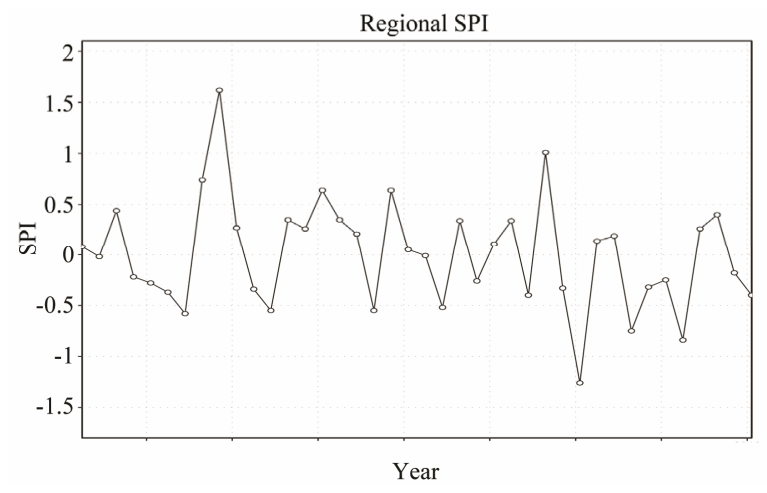

Figure 3. Schematic representation of Regional (Iringa, Mbeya, Rukwa and Ruvuma) Standardized Precipitation Index (SPI) for six month, November to April from 1970 to 2010. The period which fall outside this six month, May to October are not shown as they are normally dry. The $x$-axis is Year and $y$-axis is the amplitude deviation of SPI from normal.

Table 2. Table showing classification of SPI value and their corresponding event probability which is commonly used in southern African region adopted from Manatsa et al. [23].

\begin{tabular}{ccc}
\hline $\begin{array}{c}\text { SPI value } \\
\text { occurrence }\end{array}$ & \% Occurrence & Nominal SPI class \\
\hline$>1.645$ & $\leq 5$ & Extremely wet \\
1.644 to 1.282 & $6-10$ & Severely wet \\
0.842 to 1.281 & $11-20$ & Moderate wet \\
0.524 to 0.841 & $21-33$ & Slightly wet \\
-0.523 to 0.523 & $34-50$ & Normal \\
-0.841 to -0.524 & $21-33$ & Slightly drought \\
-1.281 to -0.842 & $11-20$ & Moderate drought \\
-1.644 to -1.282 & $6-10$ & Severely drought \\
$<-1.645$ & $\leq 5$ & Extremely drought \\
\hline
\end{tabular}

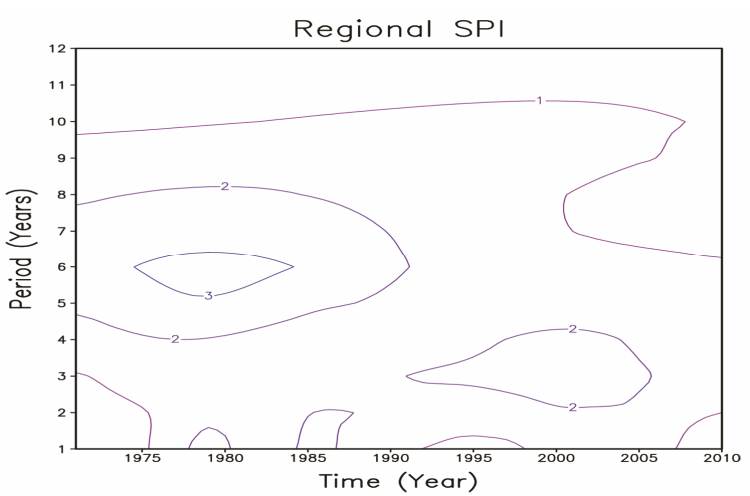

Figure 4. Wavelet power spectrum of Standardized Precipitation Index (SPI) for six month, November to April period from January 1970 to December 2010 showing the largest powers found within the region (Iringa, Mbeya, Ruvuma and Rukwa) during the study period. 
Entekhabi [15] and Indeje and Semazzi [16] among others. Furthermore, Figure 5 shows above and below normal rainfall to be dominant between the year 1978s to 1991s and the year 1999s to 2010s respectively; consistence with results presented in Table 3 .

Inspection from the regional SPI value obtained reveals that, the wettest season in record was that of 1978/1979 which can be classified as Severely wet (SPI value of 1.62) and the driest season was that of 1999/ 2000 which can be classified as Moderate drought (SPI value of -1.26) according to Manatsa et al. [23] classification presented in Table 2. Table 3 shows five (5) wettest and driest years in record for the region during the study period. Similar results have been shown by Ogallo [3] and Mapande and Reason [8,19] for the period in between 1970 to 1999 and 1970 to 1993 respectively, the period which compromise with this research work.

\subsection{Wind Flow Pattern at $850 \mathrm{hPa}$ Level and SST Anomaly}

The results presented to this point indicate that Atmos-

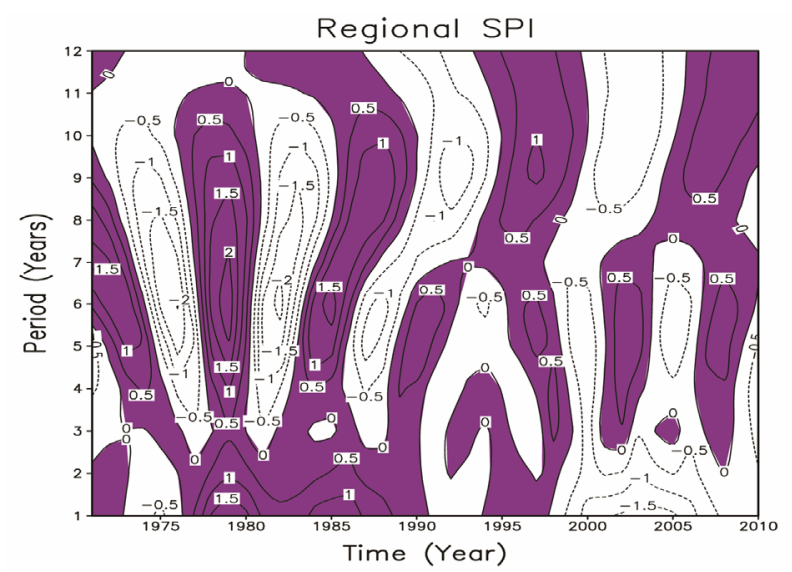

Figure 5. Wavelet representation of Standardized Precipitation Index (SPI) for six month, November to April period from January 1970 to December 2010 showing the dominant periodicity modes found within the region (Iringa, Mbeya, Ruvuma and Rukwa) during the study period.

Table 3. Table showing the wettest and driest years in records for southern highland Tanzania during the study period of 41 year, from 1970 to 2010.

\begin{tabular}{ccc}
\hline No. & Wettest years & Driest years \\
\hline 1 & $1977 / 78$ & $1976 / 77$ \\
2 & $1978 / 79$ & $1987 / 88$ \\
3 & $1984 / 85$ & $1999 / 00$ \\
4 & $1988 / 89$ & $2002 / 03$ \\
5 & $1997 / 98$ & $2005 / 06$ \\
\hline
\end{tabular}

pheric circulations over the Indian Ocean act as an important factor in influencing rainfall over East Africa. Study by Goddard and Graham [6] reveal $850 \mathrm{hPa}$ level to be most representative of the behaviour of the vertically integrated moisture flux over East Africa. This level was proposed for the purpose of reducing the effects of high grounds in some areas. Indeed, low level winds are of significant importance as the convergence of these winds may result in the development of clouds and precipitation when enough moisture content is present [2]. Thus, the data from $850 \mathrm{hPa}$ were used as most representative of the behavior of the low level winds in this region. Wettest (1997/1998) and driest (1999/2000) years were selected from Table 3 to study the dominant moisture patterns and SST anomaly. Monthly plots corresponding to the approximate beginning, peak and end periods of the rainy season over southern highland Tanzania in November, February and April are shown. Other months which tend to show anomalies that are a transition between those for November and February, and between February and April respectively, are not shown for brevity.

In November, the beginning of the rain season of the wet year indicates anomalously positive SST anomalies over the western Indian Ocean, particularly at the northeastern part of Madagascar (Figure 6(a)). Study by Webster et al. [11] reveals the same trend and suggest that, the development of this anomalous warm SST anomaly in western Indian Ocean started in June 1997 and reached its maximum in February 1998 (Figure 6(b)). At about the same time, the eastern Indian Ocean developed a strong negative SST anomaly starting in July 1997 and reached a maximum in November 1997 (Figure 6(a)). This SST anomaly pattern is evocative of the subtropical South Indian Ocean SST dipole pattern suggested by Saji et al. [12]; Behera and Yamagata [26] and tends to influence southern African summer rainfall. Over the Atlantic Ocean, positive SST anomalies are observed in the Gulf of Guinea, Namibia and Angola coast. Several studies (e.g. [8,27]) suggest that these positive SST anomalies are evocative of Benguela Nino in the tropical and southeast Atlantic Ocean. The Benguela Nino is often associated with floods in Angola and Namibia and abundant rainfall in the usually arid Namib Desert [27].

Simulated moisture patterns in November, the beginning of rain season of the wet year indicate that there is enhanced northeasterly and easterly moisture flux convergence hence increasing moisture penetration in Tanzania (Figure 7(a)). Also there is presence of enhanced cyclonic flow over northern Namibia which induces an increased flow of moist air. As a result, increased low level moisture convergence is expected over northern Zambia and southern highland Tanzania. 


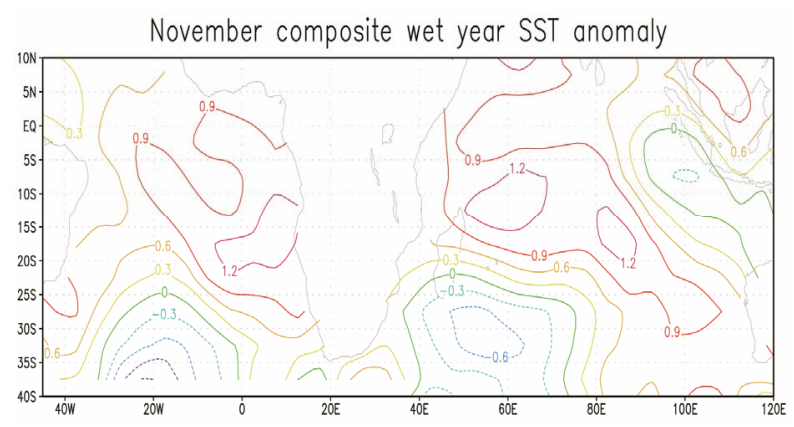

(a)

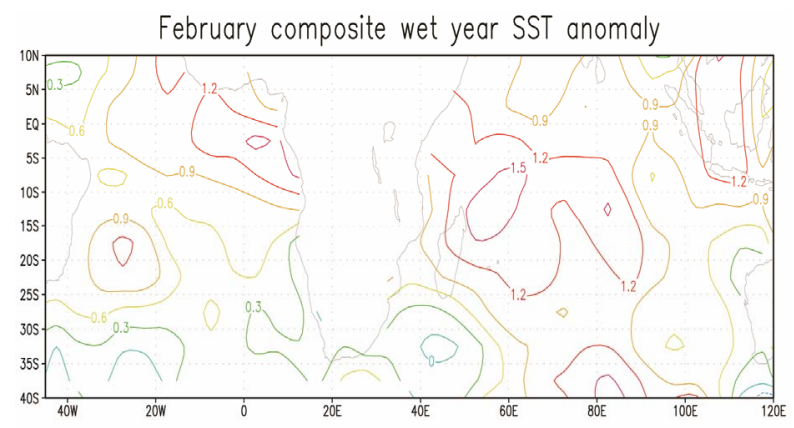

(b)

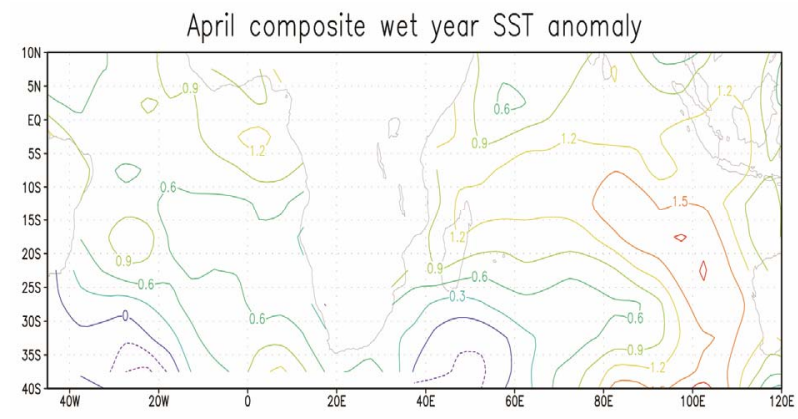

(c)

Figure 6. Composite SST anomaly during the rainy season of wet year of the 1997/98 in the Atlantic and Indian Ocean in different time. (a) November, 1997 during the beginning of rain season (b) February, 1998 during the peak of the rain season (c) April, 1998 near the end of rain season.

Another moisture source for East Africa is the tropical East Atlantic Ocean. Anomalous westerlies from East Atlantic and Congo basin oppose the easterly flux that exists at this time of year from the Indian Ocean (Figure 7(a)). As a result, relative convergence of low level moisture occurs over western Tanzania, Uganda and northern Zambia.

In February, during the peak of the rain season of the wet year anomalously positive SST anomalies is enhanced all over the tropical western Indian Ocean (Figure 6(b)). Warmer SSTs near Tanzania coast act to increase the local evaporation, and hence the low level moisture over the land. Simulated moisture pattern during this period indicates that the northeasterly wind has en- hanced and it penetrates further south (Figure 7(b)). A second source of moisture which is westerly wind from Atlantic ocean and Congo basin have also strengthened therefore transporting more moisture into great lake region and northern Mozambique (Figure 7(b)). A cyclonic center can be seen over northern Namibia due to recurving of northeasterlies to south-westerlies. Observations show that, the lower tropospheric anticyclonic anomaly over the tropical south Indian Ocean is stronger than November when the rain season started. Study by Mapande and Reason [8] suggest this anticyclonic circulation feature in November and February to be possibly part of the local atmospheric response of cool SST anomaly in the tropical south Indian Ocean. Moreover, tropical Indian Ocean is seen to be dominated by easterlies during this peak season as the result of warming of the SST in the west and cooling in the East Indian Ocean [28]. Taken together with this, the extreme continental southward location of ITCZ between Tanzania and central Mozambique during December and February [3,4, $6,7]$, suggests a substantial rainfall over southern Tanzania during this period.

Towards the end of the rainy season in April, cyclonic moisture flux anomalies (Figure 7(c)) emerge over the tropical equatorial western Indian Ocean consistent with the small warm SST anomalies (Figure 6(c)) in those regions. The anomalous positive SST anomaly at Indian Ocean is seen to shift toward the East of the Indian Ocean. The presence of strong southeasterly moisture flux which is fed by south western Indian Ocean region imply strong moisture is fetch toward East Africa and Congo basin. Such conditions are favorable for ongoing agricultural activities which are taking place during this time of the year.

During dry year of 1999/2000, simulation of $850 \mathrm{hPa}$ level wind pattern show the equatorial westerlies and south Indian Ocean trade winds are reversed from those of wet scenario described above for 1997/1998. In November, during the beginning of the rain season of the dry year indicates anomalously positive SST anomalies in eastern Indian Ocean, while the western part is dominated by near normal SST (Figure 8(a)). The same scenario can be seen over eastern Atlantic Ocean where near normal SST is observed. The inverse is true for the wet scenario discussed above (Figure 6(a)). Simulated moisture pattern during the beginning of rainy season of the dry year is dominated by northeasterly and weak easterly wind (Figure 9(a)). A weak cyclonic flow is seen to develop at the western Indian Ocean due to the cool SST at this region of the ocean. Also there is westerly wind observed at the tropical center Indian Ocean which denies moisture transport to Tanzania as the result of turning southeasterly wind.

In February, during the peak of the rain season of the dry year (Figure 8(b)), anomalously negative SST 


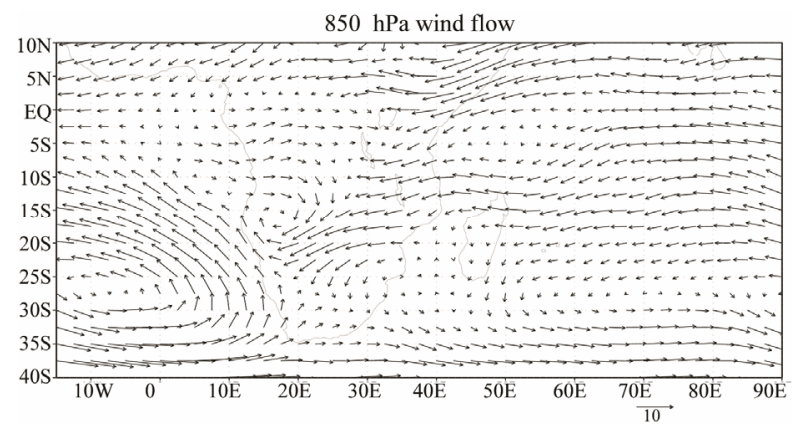

(a)

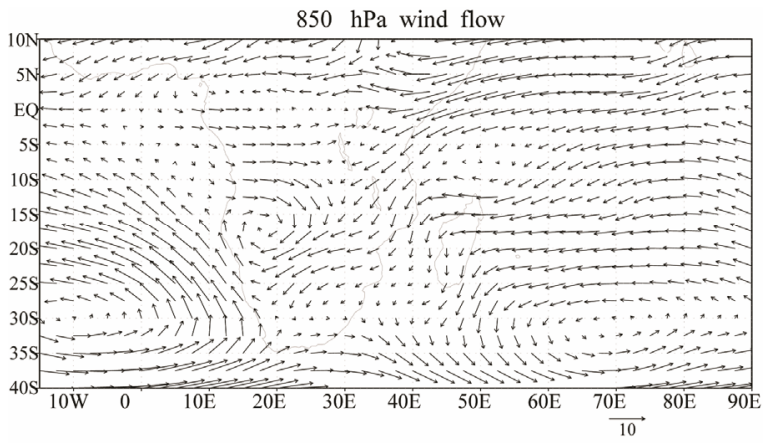

(b)

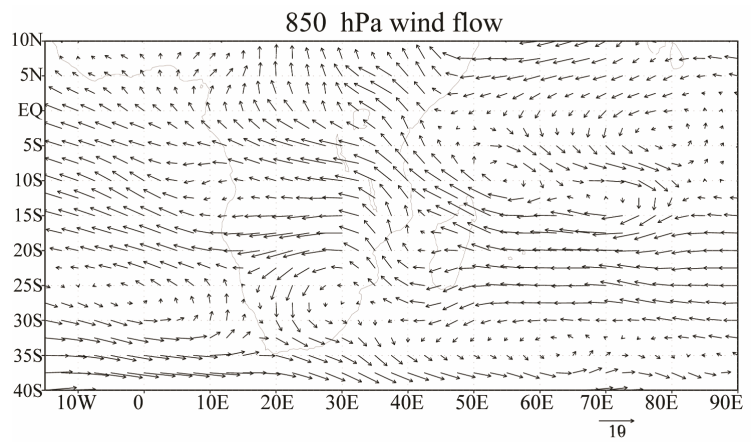

(c)

Figure 7. Simulated moisture pattern during the rainy season of the wet year of $1997 / 98$ at $850 \mathrm{hPa}$ level $\left(\mathrm{ms}^{-1}\right)$. (a) November, 1997 during the beginning of rain season (b) February, 1998 during the peak of the rain season (c) April, 1998 near the end of rain season.

anomalies is developed over south western Indian Ocean. Simulation moisture flux at this period indicates a lower tropospheric anticyclone flow over western Indian Ocean right at Tanzania coast and cyclonic flow near northern Namibia (Figure 9(b)). The northeasterly moisture flux anomaly over the western Indian Ocean turns more north and south due to the presence of anticyclone thereby denying inland penetration of moisture. Not only that, but also strong westerlies wind is seen over western Indian Ocean, as the result more moisture is transport moisture away from mainland Tanzania. In comparison to the scenario of the wet year (Figure 7(b)), there is a stronger divergence of moisture from the Indian Ocean during this period. Over the Congo Basin, the easterly moisture flux is also turning northward different from the case seen during wet year (Figure 7(b)) thus, further export of moisture away from the country. Little moisture found in Tanzania is also exported to Madagascar by northeasterly and westerlies wind. As it was the case for the wet scenario, a cyclonic center can be seen over northern Namibia as the result of recurving of northeasterlies to southwesterlies.

In April, near the end of the rainy season of the dry year (Figure 8(c)), positive SST anomaly emanate at southwestern Indian Ocean which led to development of anticyclone flow. Simulation of the moisture flux indicates the easterly over southwestern Indian Ocean

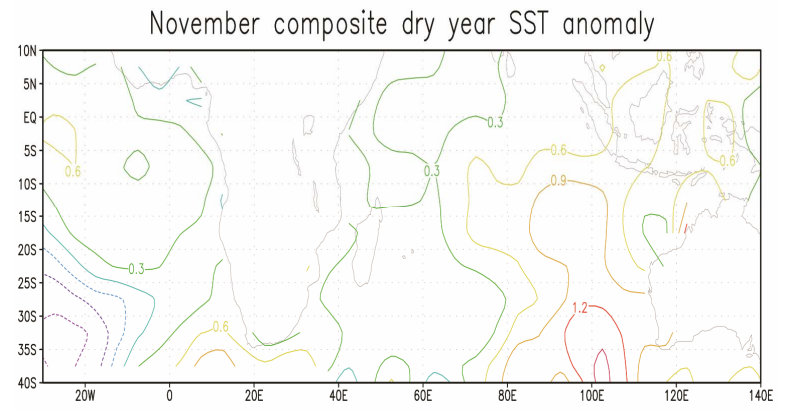

(a)

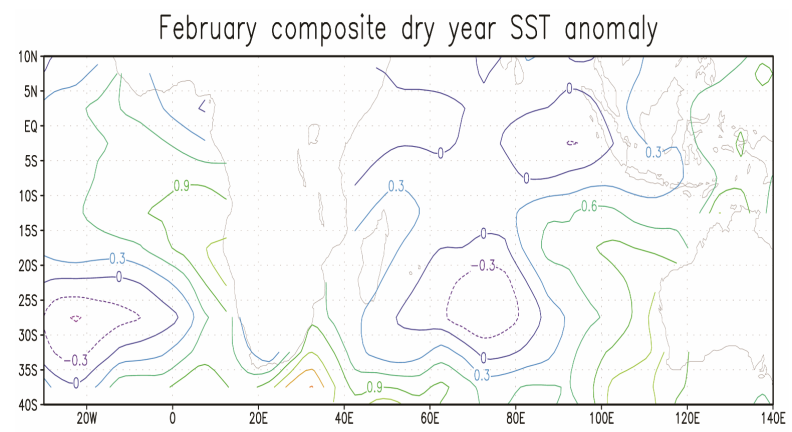

(b)

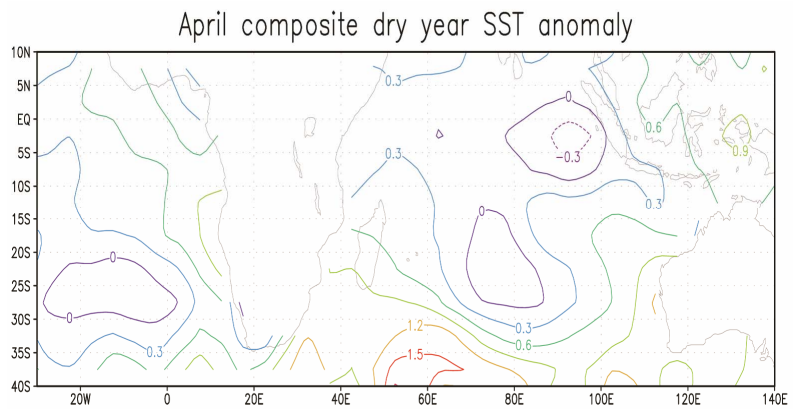

(c)

Figure 8. Composite SST anomaly during the rainy season of dry year of the 1999/00 in the Atlantic and Indian Ocean at different time. (a) November, 1999 during the beginning of rain season (b) February, 2000 during the peak of the rain season (c) April, 2000 near the end of rain season. 


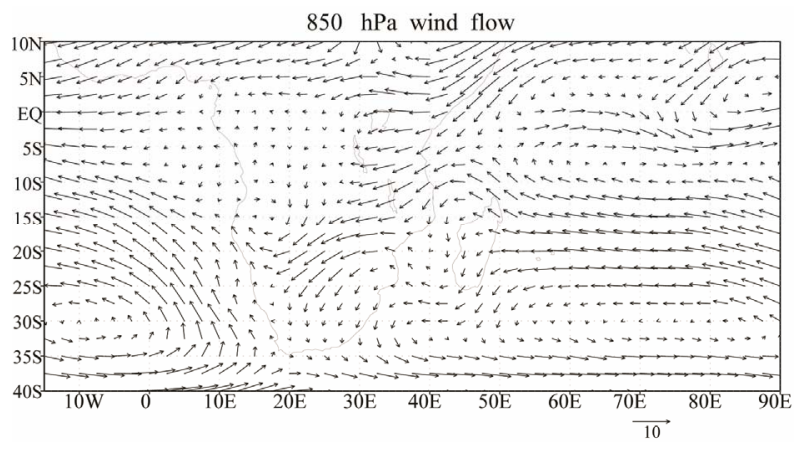

(a)

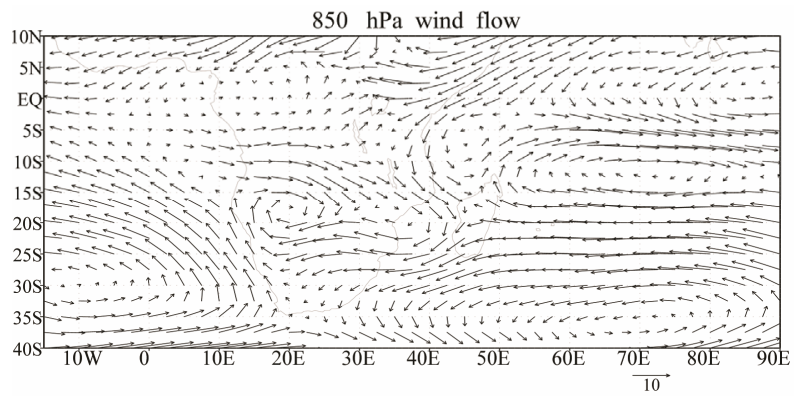

(b)

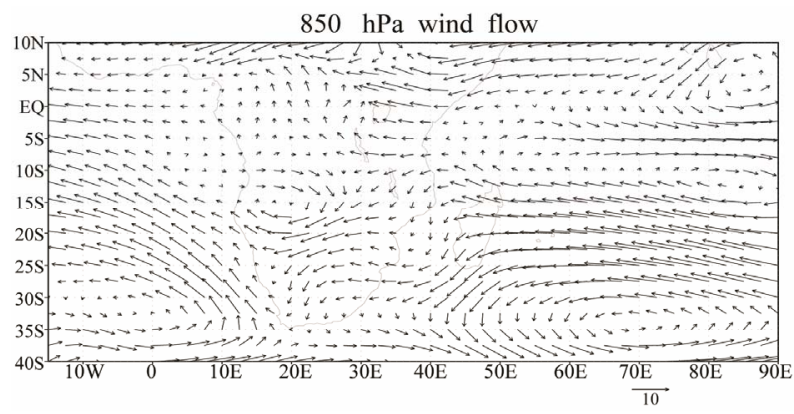

(c)

Figure 9. Simulated moisture pattern during the rainy season of the dry year of $1999 / 00$ at $850 \mathrm{hPa}$ level $\left(\mathrm{ms}^{-1}\right)$. (a) November, 1999 during the beginning of rain season (b) February, 2000 during the peak of the rain season (c) April, 2000 near the end of rain season.

(Figure 9(c)) turns more southerly due to development of this anticyclone. On the other hand the northeasterly turn more north over the East Africa coast due to development of weak cyclone and cross equatorial westerly over the Indian Ocean thereby denying inland penetration of moisture to Tanzania. It can also be seen that, there is weak westerly from Congo basin converge with the easterly from Kenya at Lake Victoria basin.

In general, for wet year the moisture flux pattern and SST anomaly plots suggest enhanced convective precipitation over Tanzania to be associated with low level moisture flux from the northeast and southeast Indian Ocean followed by tropical Atlantic Ocean and Congo basin. For the case of dry years, simulation of moisture flux pattern suggest weak easterly propagating wind to be more apparent over Tanzania coast followed by weak low level moisture flux from Atlantic Ocean and Congo basin due to the dominance of cool SST. Since the pattern of winds during the wet years are opposite to that of the dry years, their reversal provide credence to the suggestion by Goddard and Graham [6]; Mapande and Reason [8] and Mpeta and Jury [9] that the modulation of the atmospheric circulation over the Indian ocean is important factor in influencing rainfall over Tanzania regardless of how much incoming moisture content turns in Mozambique Channel at the beginning of rain season.

\section{Conclusions}

The climate characteristic of southern highland Tanzania was studied. It was found that rainfall over the region is linked with the sea surface temperature over the Indian Ocean, where warmer (cooler) western Indian Ocean is accompanied by high (low) amount of rainfall over most part of the Tanzania. During wet (dry) years, weaker (stronger) equatorial westerlies and anticyclone (cyclonic) anomaly over the southern tropics act to reduce (enhance) the export of equatorial moisture away from East Africa. Not only that, but also moisture influx from the northeast Indian monsoon has significant influence on the rainfall over the region. During the wet years, strong northeasterly Indian monsoon is evident over most of Tanzania while during the dry year the northeasterly is seen to turn north hence denying moisture influx over Tanzania. In addition, increased (decreased) low level moisture influx from gulf of Guinea and Congo basin tend to occur during the wet (dry) seasons, leading to enhanced (reduced) low level moisture convergence over western part of Tanzania.

Although there are some variations in magnitude of the anomalies for each year, the region is experiencing normal rainfall. The results suggest the wettest season in record during the study period to be 1978/1979 which can be classified as severely wet and the driest season to be 1999/2000 which can be classified as moderate drought. Furthermore, analysis of rainfall amount received throughout the study period shows that dominance of above normal rainfall condition during 1978s to 1991s and below normal condition during 2000s to 2010 s. Different dominant periodicity modes have been observed over the study period, but two of them seem to be more dominant over the whole study period. These modes of rainfall have been identified at time scale of 1.5 and 6 years which may be associated with the quasi biennial oscillation (QBO) and El Nino Southern Oscillation (ENSO) respectively.

\section{REFERENCES}

[1] T. A. Kabanda and M. R. Jury, "Interannual Variability of 
Short Rains over Northern Tanzania," Climate Research, Vol. 13, No. 3, 1999, pp. 231-241. doi:10.3354/cr013231

[2] E. J. Mpeta, "Mechanisms of Interannual Rainfall Variability over Tropical Highlands of Africa and Its Predictability Potential," Ph.D. Thesis, Department of Geography and Environmental Studies, University of Zululand, Empangeni, 2002.

[3] L. A. Ogallo, "Dynamics of the East African Climate," Journal of Earth System Science, Vol. 102, 1993, pp. 203-217.

[4] S. K. Behera, J. Luo, S. Masson, T. Yamagata, P. Delecluse, S. Gualdi and A. Navarra, "Paramount Impact of the Indian Ocean Dipole on the East African Short Rains: A CGCM Study," Journal of Climate, Vol. 18, No. 21, 2005, pp. 4514-4530. doi:10.1175/JCLI3541.1

[5] M. Latif, D. Dommenget, M. Dima and A. Grotzner, "The Role of Indian Ocean Sea Surface Temperature in Forcing East African Rainfall Anomalies during December-January 1997/98," Journal of Climate, Vol. 12, No. 12, 1999, pp. 3497-3504.

[6] L. Goddard and N. E. Graham, "Importance of the Indian Ocean for Simulating Rainfall Anomalies over Eastern and Southern Africa," Journal of Geophysical Research, Vol. 104, No. d16, 1999, pp.19,099-19,116.

[7] M. Indeje, F. H. M. Semazzi and L. J. Ogallo, "ENSO Signals in East African Rainfall Seasons," International Journal of Climatology, Vol. 20, No. 1, 2000, pp. 19-46. doi:10.1002/(SICI)1097-0088(200001)20:1<19::AID-JO C449>3.0.CO;2-0

[8] A. T. Mapande and C. J. C. Reason, "Links between Rainfall Variability on Intraseasonal and Interannual Scales over Western Tanzania and Regionacirculation and SST Patterns," Meteorology and Atmospheric Physics, Vol. 89, No. 1-4, 2005, pp. 215-234. doi:10.1007/s00703-005-0130-2

[9] E. J. Mpeta and M. R. Jury, "Intraseasonal Convective Structure and Evolution over Tropical East Africa," Climate Research, Vol. 17, No. 1, 2001, pp. 83-92. doi: $10.3354 / \mathrm{cr} 017083$

[10] H. K. Ntale and T. Y. Gan, "East African Rainfall anomaly Patterns in Association with El Nino Southern Oscillation," Journal of Hydrologic Engineering, Vol. 9, No. 4, 2004, pp. 257-268. doi:10.1061/(ASCE)1084-0699(2004)9:4(257)

[11] P. J. Webster, J. P. Loschnigg, A. M. Moore and R. R. Leben, "Coupled Ocean-Atmosphere Dynamics in the Indian Ocean during 1997-98," Nature, Vol. 401, No. 6751, 1999, pp. 356-360. doi:10.1038/43848

[12] N. H. Saji, B. N. Goswami, P. N. Vinayachandran and T. Yamagata, "A Dipole Mode in the Tropical Indian Ocean,” Nature, Vol. 401, No. 6751, 1999, pp. 360-363. doi:10.1038/43855

[13] C. O. Clark, P. J. Webster and J. E. Cole, "Interdecadal Variability of the Relationship between the Indian Ocean Zonal Mode and East African Coastal Rainfall Anomalies," Journal of Climate, Vol. 16, No. 3, 2003, pp. 548-554.

doi:10.1175/1520-0442(2003)016<0548:IVOTRB $>2.0 . C$ $\underline{\mathrm{O} ; 2}$
[14] C. P. K. Basalirwa, J. O. Odiyo, R. J. Mngodo and E. J. Mpeta, "The Climatological Regions of Tanzania Based on the Rainfall Characteristics," International Journal of Climatology, Vol. 19, No. 1, 1999, pp. 69-80.

doi:10.1002/(SICI)1097-0088(199901)19:1<69::AID-JO C343>3.0.CO;2-M

[15] S. E. Nicholson and D. Entekhabi, "The Quasi Periodic Behavior of Rainfall Variability in Africa and Its Relationship to the Southern Oscillation," Archives for Meteorology, Geophysics and Bioclimatology, Vol. 34, No. 3-4, 1986, pp. 311-348.

[16] M. Indeje and F. H. M. Semazzi, "Relationships between QBO in the Lower Equatorial Stratospheric Zonal Winds and East African Seasonal Rainfall," Meteorology and Atmospheric Physics, Vol. 73, No. 3-4, 2000, pp. 227-244. doi: $10.1007 / \mathrm{s} 007030050075$

[17] E. Kalnay, M. Kanamitsu, R. Kistler, W. Collins, D. Deaven, L. Gandin, M. Iredell, S. Saha, G. White, J. Woollen, Y. Zhu, M. Chelliah, W. Ebisuzaki, W. Higgins, J. Janowiak, K. C. Mo, C. Ropelewski, J. Wang, A. Leetmaa, R. Reynolds, R. Jenne and D. Joseph, "The NCEP/NCAR 40 Year Reanalysis Project," Bulletin of American Meteorology Society, Vol. 77, No. 3, 1996, pp. 437-471. doi:10.1175/1520-0477(1996)077<0437:TNYRP $>2.0 . C O$ ;2

[18] A. Kaplan, M. A. Cane, Y. Kushnir, A. C. Clement, M. B. Blumenthal and B. Rajagopalan, "Analyses of Global Sea Surface Temperature 1856-1991," Journal of Geophysical Research, Vol. 103, No. C9, 1998, pp. 18,567-18,589. doi:10.1029/97JC01736

[19] A. T. Mapande, and C. J. C. Reason, "Interannual Rainfall Variability over Western Tanzania," International Journal of Climatology, Vol. 25, No. 10, 2005, pp. 13551368. doi:10.1002/joc. 1193

[20] T. B. McKee, N. J. Doesken and J. Kleist, "The Relationship of Drought Frequency and Duration to Time Scales," 8th Conference on Applied Climatology, Anaheim, 1993, pp. 179-184.

[21] N. B. Guttman, "Accepting the Standardized Precipitation Index, A Calculation Algorithm," Journal of the American Water Resources Association, Vol. 35, No. 2, 1999, pp. 311-322. doi:10.1111/j.1752-1688.1999.tb03592.x

[22] I. Bordi, S. Frigio, P. Parenti, A. Speranza and A. Sutera, "The Analysis of the Standardized Precipitation Index in the Mediterranean Area; Large Scale Patterns," Annal Sgeofisica, Vol. 44, No. 5-6, 2001, pp. 965-978.

[23] D. Manatsa, G. Mukwada, E. Siziba and T. Chinyanganya, "Analysis of Multidimensional Aspects of Agricultural Droughts in Zimbabwe Using the Standardized Precipitation Index (SPI)," Theoretical and Applied Climatology, Vol. 102, No. 3-4, 2010, pp. 287-305. doi:10.1007/s00704-010-0262-2

[24] R. R. Heim, "A Review of Twentieth Century Drought Indices Used in the United States," American Meteorological Society, Vol. 83, No. 8, 2002, pp. 1149-1165.

[25] B. Lloyd-Hughes and M. A. Saunders, "A Drought Climatology for Europe," International Journal of Climatology, Vol. 22, No. 13, 2002, pp. 1571-1592. 


\section{doi:10.1002/joc. 846}

[26] S. K. Behera and T. Yamagata, "Subtropical SST Dipole Events in the Southern Indian Ocean," Geophysical Research Letters, Vol. 28, No. 2, 2001, pp. 327-330. doi:10.1029/2000GL011451

[27] P. Florenchie, J. R. E. Lutjeharms, C. J. C. Reason, S. Masson and M. Rouault, "The Source of Benguela Ninos in the South Atlantic Ocean," Geophysical Research Letters, Vol. 30, No. 10, 2003, 4 pp. doi:10.1029/2003GL017172

[28] S. K. Behera and T. Yamagata, "Influence of the Indian Ocean Dipole on the Southern Oscillation," Journal of the Meteorological Society of Japan, Vol. 81, No. 1, 2003, pp. 169-177. doi:10.2151/jmsj.81.169 